\title{
Global human "predation" on plant growth and biomass
}

\author{
David G. Jenkins $^{1}$ (D) | Helmut Haberl ${ }^{2}$ (D) | Karl-Heinz Erb² $\quad$ Andrew L. Nevai ${ }^{3}$
}

${ }^{1}$ Department of Biology, University of Central Florida, Orlando, FL, USA

${ }^{2}$ Institute of Social Ecology, University of Natural Resources and Life Sciences, Vienna, Vienna, Austria

${ }^{3}$ Department of Mathematics, University of Central Florida, Orlando, FL, USA

\section{Correspondence}

David G. Jenkins, Department of Biology, University of Central Florida, 4110 Libra Drive, Orlando, FL 32816, USA.

Email: david.jenkins@ucf.edu

Editor: Irena Simova

\begin{abstract}
Aim: Ecological theory is not often applied to human appropriation of net primary production (HANPP), which estimates reduction of natural net primary production (NPP) due to harvest and land use. Here we use predator-prey theory to evaluate HANPP as "predation". Macroecology and adaptive life history strategies also help evaluate relationships among global terrestrial HANPP, NPP, and plant biomass (B). Location: Lands worldwide.

Time period: 2000 .

Major taxa studied: Terrestrial plants.

Methods: HANPP and potential NPP allometric scaling were estimated for terrestrial ecoregions ( $N=819$, for $86 \%$ of global land surface area) in the year 2000 . HANPP and NPP scaling were compared and projected to current and year 2050 conditions. NPP scaling for potential versus actual conditions were also compared, as were biomass turnover rates ( $T$; per year).

Results: Global HANPP scales predictably with B; consistent with predator-prey theory, HANPP scaling is not clearly satiated at greater B. NPP scaling supports adaptive life history strategies theory. HANPP scaling is c. $16 \%$ of NPP scaling; a conservative estimate compared to a grid-based 22\%. HANPP scaling could become $25-35 \%$ of potential NPP scaling by 2050 due to population growth, or be constrained to $20-26 \%$ of potential NPP scaling if resource use efficiency improves. However, B is more sensitive than NPP to human effects, and human population size and HANPP now dominate as predictors of $T$.

Main conclusions: Three ecological theories converged here to broadly support prior empirical estimates and enable novel insights. $B$ and $T$ are more sensitive to global human impacts than is NPP and should be priorities for carbon budgets and conservation. Human population growth and resource use efficiency strongly affect terrestrial plant HANPP, B and T, and thus global carbon budget. Both human "top-down" effects (evaluated here) and "bottom-up" drivers (e.g., climate, nutrients, $\mathrm{CO}_{2}$ ) need to be incorporated into global carbon models.
\end{abstract}

\section{KEYWORDS}

adaptive strategies theory, allometric scaling, biomass turnover rate, HANPP, macroecology, metabolic theory, NPP, plant biomass, predator-prey theory 


\section{1 | INTRODUCTION}

While modifying and using $>75 \%$ of terrestrial land area (Pandit et al., 2018), humans appropriate a substantial portion of global terrestrial annual plant growth (Haberl, Erb, \& Krausmann, 2014; Imhoff et al., 2004; Vitousek, Ehrlich, Ehrlich, \& Matson, 1986). For example, annual crop growth per unit area is often less than in primary forests cleared for those crops, and plant growth in urban areas is typically reduced by paved and roofed areas. Plant growth is known as net primary production (NPP), and is quantified as a rate $\left(\mathrm{g} \mathrm{C} / \mathrm{m}^{2} /\right.$ year; Table 1). Human appropriation of NPP (HANPP; also g C/m²/year; Table 1) quantifies human impacts on NPP, including the sum of harvest and land use-related changes (e.g., agriculture, timber harvesting, urban development; Haberl et al., 2014). This definition of HANPP builds on earlier work (Vitousek et al., 1986; Whittaker \& Likens, 1973; Wright, 1990) and is more inclusive than most earlier definitions (Haberl et al., 2014). In turn, the portion not appropriated by humans quantifies NPP available for the planet's remaining biodiversity and sustained ecosystem function. Accordingly, HANPP research has influenced discussions of sustainable population growth, conservation planning, planetary "tipping points", and the Anthropocene (e.g., Barnosky et al., 2012; Ellis et al., 2013; Foley et al., 2005; Mellody et al., 2014; Running, 2012). HANPP focuses on terrestrial ecosystems and complements other analyses of nonrenewable resources (e.g., Brown et al., 2014; Meadows, Meadows, Randers, \& Behrens III, 1972; Sabin, 2013) as a measure of our collective impact. Comparison of NPP and HANPP directly relates to global carbon analyses because NPP is related to removal of $C$ from the atmosphere by plants, whereas HANPP contributes to increased atmospheric $\mathrm{C}$.

Global HANPP has been estimated for over 40 years using different definitions and increasingly sophisticated methods (see review by Haberl et al., 2014). Those differences mean that estimates cannot be easily compared, but recent values (i.e., after 1970s in table 1 of Haberl et al., 2014) average $24 \pm 10 \%$ (standard deviation) of potential NPP; a large impact by humans. Human effects on global plant biomass ( $\mathrm{B} ; \mathrm{g} \mathrm{C} / \mathrm{m}^{2}$; Table 1 ) and turnover have also been quantified (e.g., Erb et al., 2016, 2018).

Analyses of global HANPP and human effects on B quantify land use changes and effects on the global carbon cycle, but have not been evaluated through the lens of ecological theory. If ecological theory is general (i.e., not peculiar to specific ecological systems), it should: work at global scales; apply to humans; predict relationships among HANPP, NPP and B; and offer an explanatory basis for models of these variables that are vital to ecosystem ecology, global carbon cycling and sustainable human use of natural resources. In turn, using ecological theory to evaluate global HANPP, NPP and $B$ tests that theory and helps to unite it with sustainability science (e.g., Opdam, Luque, Nassauer, Verburg, \& Wu, 2018).

Here we apply predator-prey theory to evaluate global HANPP as "top-down" regulation of plants in the sense of a food chain, where humans are the predator and "predation" on plants includes all effects in the definition of HANPP. This view complements "bottom-up" estimates of NPP based on plant biology, $\mathrm{CO}_{2}$ enrichment

TAB LE 1 Terms used in this work, with definitions, acronyms, units, meanings and uses

\begin{tabular}{|c|c|c|c|c|}
\hline Term & Acronym & Units & What it measures & How it is used \\
\hline $\begin{array}{l}\text { Potential net primary } \\
\text { production }\end{array}$ & $\mathrm{NPP}_{\text {pot }}$ & $\mathrm{g} \mathrm{C} / \mathrm{m}^{2} /$ year & $\begin{array}{l}\text { Potential plant growth rate, for natural } \\
\text { conditions }\end{array}$ & $\begin{array}{l}\mathrm{NPP}_{\text {pot }} \sim \mathrm{B} ; \text { natural NPP } \\
\text { scaling }\end{array}$ \\
\hline Actual net primary production & $\mathrm{NPP}_{\text {act }}$ & $\mathrm{g} \mathrm{C} / \mathrm{m}^{2} /$ year & $\begin{array}{l}\text { Actual plant growth rate, after human } \\
\text { land use effects }\end{array}$ & $\begin{array}{l}\text { NPP }_{\text {act }} \sim \text { B; recent (year } \\
2000 \text { ) NPP scaling }\end{array}$ \\
\hline $\begin{array}{l}\text { Ecological net primary } \\
\text { production }\end{array}$ & $\mathrm{NPP}_{\text {eco }}$ & $\mathrm{g} \mathrm{C} / \mathrm{m}^{2} /$ year & $\begin{array}{l}\text { Actual plant growth, after human land use } \\
\text { effects and harvest }\end{array}$ & $\begin{array}{l}\text { As part of HANPP estimates } \\
\left(\mathrm{HANPP}=\mathrm{NPP}_{\text {pot }}-\mathrm{NPP}_{\text {eco }}\right)\end{array}$ \\
\hline $\begin{array}{l}\text { Human appropriation of net } \\
\text { primary production }\end{array}$ & HANPP & $\mathrm{g} \mathrm{C} / \mathrm{m}^{2} /$ year & $\begin{array}{l}\text { Human use of plant growth, including land } \\
\text { use }\left(\mathrm{HANPP}_{\text {lu }}\right) \text { and harvest }\left(\mathrm{HANPP}_{\text {harv }}\right)\end{array}$ & $\begin{array}{l}\text { HANPP B; estimate } \\
\text { of human functional } \\
\text { response, in the sense of } \\
\text { predator-prey theory }\end{array}$ \\
\hline Potential plant biomass & $B_{\text {pot }}$ & $\mathrm{g} \mathrm{C} / \mathrm{m}^{2}$ & $\begin{array}{l}\text { Potential, aboveground + belowground } \\
\text { plant mass in an area, for natural } \\
\text { conditions }\end{array}$ & $\begin{array}{l}\text { As the predictor axis for } \\
\text { allometric scaling of } \\
\text { NPP }_{\text {pot }}, \text { HANPP and } T_{\text {pot }}\end{array}$ \\
\hline Actual plant biomass & $\mathrm{B}_{\text {act }}$ & $\mathrm{g} \mathrm{C} / \mathrm{m}^{2}$ & $\begin{array}{l}\text { Actual, aboveground + belowground plant } \\
\text { mass in an area, after human effects }\end{array}$ & $\begin{array}{l}\text { As the predictor axis for } \\
\text { allometric scaling of } \\
\mathrm{NPP}_{\text {act }} \text { and } T_{\text {act }}\end{array}$ \\
\hline $\begin{array}{l}\text { Potential plant biomass turnover } \\
\text { rate }\end{array}$ & $T_{\text {pot }}$ & Per year & $\begin{array}{l}\text { Potential rate that biomass changes (as } \\
\text { in a slope coefficient for NPP/B), for } \\
\text { natural conditions }\end{array}$ & $\begin{array}{l}\text { Allometric scaling of natural } \\
T \text {; how } T \text { is predicted } \\
\text { by plant } B \text { in natural } \\
\text { conditions }\end{array}$ \\
\hline $\begin{array}{l}\text { Actual plant biomass turnover } \\
\text { rate }\end{array}$ & $T_{\text {act }}$ & Per year & $\begin{array}{l}\text { Actual rate that biomass changes (as in } \\
\text { a slope coefficient for NPP/B), after } \\
\text { human effects }\end{array}$ & $\begin{array}{l}\text { Allometric scaling of actual } \\
T \text {; how } T \text { is predicted by } \\
\text { plant } B \text { and human effects }\end{array}$ \\
\hline
\end{tabular}


and climate conditions (e.g., Körner, 2015; Malhi et al., 2015). Ultimately, both perspectives will likely prove valuable in more integrative global ecosystem models. We use a confluence of three ecological theories (predator-prey, macroecology, and adaptive life history strategies; Figure 1) to investigate relationships between HANPP, NPP and B (Brown 1995; Grime \& Pierce, 2012; Holling, 1959; May, 1977; Noy-Meir, 1975). Below is a brief synopsis of each theory as it applies here, and the confluence between them.

\section{1 | Graphical predator-prey theory}

Graphical predator-prey theory evaluates and then compares two curves. Predator consumption and prey growth are each expressed as a function of prey quantity (Figure 1a,b; May, 1977; Noy-Meir, 1975). A predator consumption curve is also known as a functional response and classically expected to be linear, asymptotic or sigmoidal in shape (Types I-III, respectively), where the shape of the curve indicates behaviour of a predator population (Holling, 1959). A linear Type I curve means predator consumption tends to increase proportionally with prey abundance (i.e., without satiation), whereas a Type II curve means predator consumption slows with satiation (Figure 1a). Humans follow a Type I curve at local or regional spatial scales (Kahlert, Fox, Heldbjerg, Asferg, \& Sunde, 2015; Van Deelen \& Etter, 2003), but a human functional response for global 'consumption' of plant material (i.e., HANPP) is unknown. If supported, such a response is a strong test of the generality of this concept. A Type III curve occurs when predators switch to the subject prey (here plants) when it reaches greater abundance. Here Types I or II are possible, but Type III would need a prior resource and does not apply.

Predator functional responses have been developed to describe individual predators or local populations; we here extend that analysis to the global human population. This extension is justifiable because: (a) humans are dominant, hyperkeystone, super-predators (Darimont, Fox, Bryan, \& Reimchen, 2015; Vitousek, Mooney, Lubchenco, \& Melillo, 1997; Worm \& Paine, 2016); (b) the human population now outweighs all wild mammals (Bar-On, Phillips, \& Milo, 2018), consistent with our role as a dominant global population; (c) the human population acts globally on terrestrial plants, as evidenced by $>2$ trillion $\mathrm{kg}$ of agricultural and forestry products transported annually (Chatham House, 2018); and (d) HANPP is common to nearly all human socioeconomic and cultural groups.

The other half of predator-prey theory is the prey growth curve (Figure 1b; here NPP B). Original models expected a hump-shaped curve because only new green growth was considered (May, 1977; Noy-Meir, 1975), and so the curve declined with greater B as stems, etc. contributed proportionally more to total B. For global terrestrial NPP (here representing all aboveground and belowground growth, including woody stems and roots), the curve should not be humpshaped but instead rise to an asymptote (Jenkins \& Pierce, 2017).

Graphical predator-prey theory compares predator functional response and prey growth curves (Figure 1a,b; May, 1977; Noy-Meir, 1975). As long as predator consumption is less than prey growth (where totals are evaluated by area under each curve), the predator
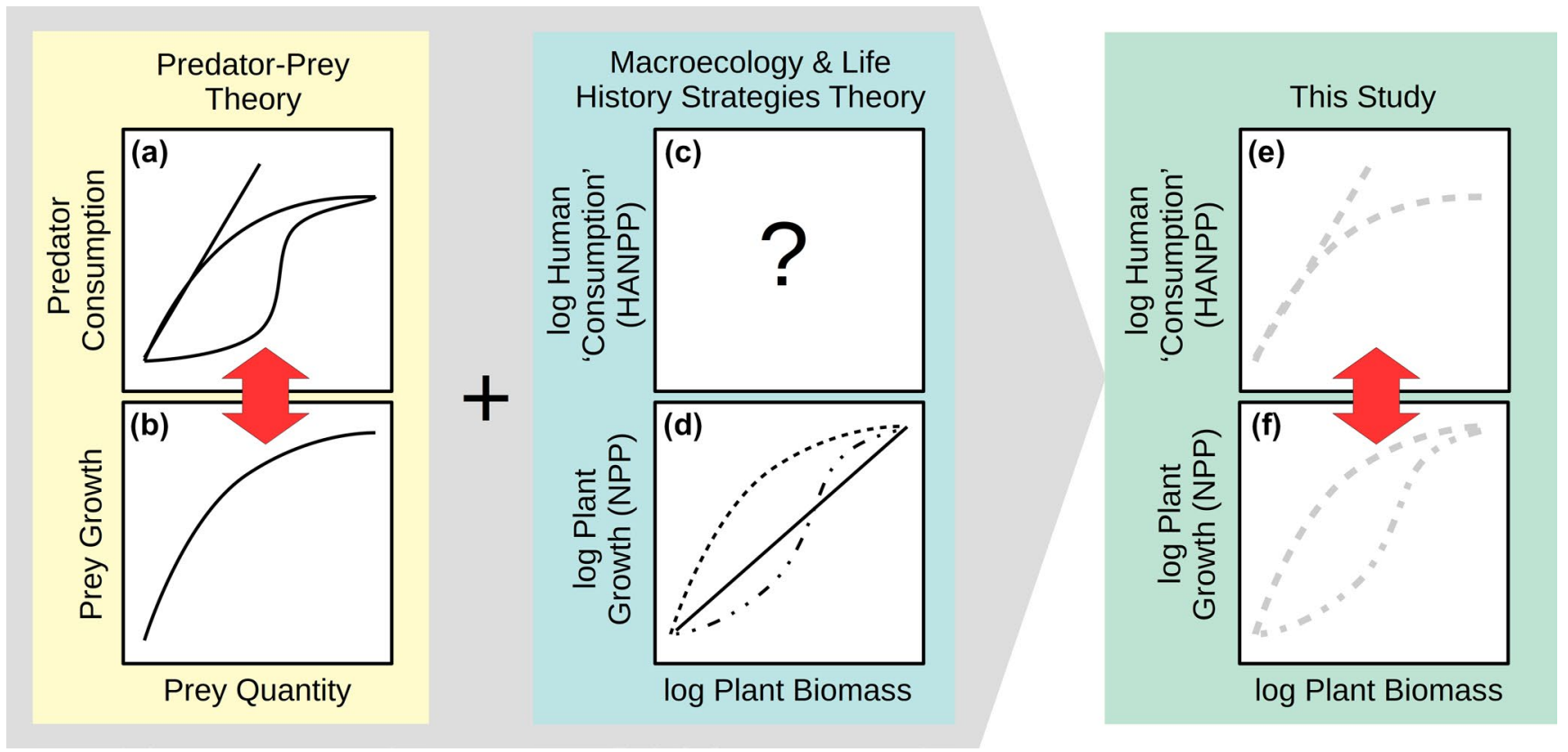

FIGURE 1 Three ecological theories unified to analyse global human "consumption" of plants. (a,b) Graphical predator-prey theory compares predator consumption (a) and prey growth (b) as a function of prey quantity. (c,d) Macroecology theory uses allometric scaling (based on logarithmic axes) to find general patterns across wide-ranging data. It has not been applied to human appropriation of net primary production (HANPP) (c), but has been used for plant net primary production (NPP) as a function of plant biomass (B), where metabolic theory predicts linear plots in log-log space (d). At wider ranges of B, curved patterns arise, consistent with adaptive life history strategies theory. $(\mathrm{e}, \mathrm{f})$ Work here uses a predator-prey context to evaluate alternative curves and compare HANPP and NPP scaling [Colour figure can be viewed at wileyonlinelibrary.com] 
and prey can coexist. If the predator consumption curve intersects the prey growth curve, a stable or unstable equilibrium may occur, depending on the location of the intersection (May, 1977; Noy-Meir, 1975; Scheffer, 2009). This theory is a basis for subsequent research on alternative stable states and thresholds (e.g., Beisner, Haydon, \& Cuddington, 2003; Scheffer, 2009).

\section{2 | Macroecology and allometric scaling}

Predator-prey theory as outlined above originally used linear scales (Figure 1a,b; May, 1977; Noy-Meir, 1975), where prey quantity (e.g., biomass) is the independent predictor for both predator consumption rate and prey growth rate. Biomass is also commonly used as an independent axis in allometric scaling and in macroecology (Brown, 1995), where "scaling" describes how a response (e.g., metabolic rate) "scales" with biomass. Unlike original predator-prey theory, allometric scaling axes are log-transformed because: growth happens exponentially; data (and model errors) are multiplicative; data span orders of magnitude; and regression assumptions are better met (Kerkhoff \& Enquist, 2009; Mascaro, Litton, Hughes, Uowolo, \& Schnitzer, 2013).

Allometric scaling has not been applied to HANPP (Figure 1c), but NPP scaling has been extensively researched, especially to test predictions of metabolic theory (e.g., Brown, Gillooly, Allen, Savage, \& West, 2004; Enquist, Brown, \& West, 1998; West, Brown, \& Enquist, 1999). Metabolic theory is based on fractal vascular tissues, and like other fractal patterns (e.g., fractal river basins; Rodriguez-Iturbe \& Rinaldo, 2001), linear scaling patterns in log-log space are expected. NPP scaling analyses within various systems (e.g., grasslands or forests) have straight linear patterns in log-log space and fit metabolic theory (e.g., Enquist et al., 1998; Jenkins, 2015). However, those analyses also have ranges of NPP and B that are narrower than the global analyses conducted here. At a wider scope of NPP and B (e.g., grasslands and forests), NPP scaling bends away from expectations of metabolic theory (Figure 1d), consistent with theory (summarized below) that expects adaptive life histories to affect growth and size in different ecological conditions (Grime \& Pierce, 2012; Jenkins \& Pierce, 2017).

\section{3 | Adaptive life history strategies theory}

Adaptive life history strategies theory focuses on competitive, stress-tolerant and ruderal strategies (and intermediates) and is predictive for productivity (Grime \& Pierce, 2012). Plants that exhibit competitive life history strategies can reach large body sizes that have greatest NPP (rather than senesce; Stephenson et al., 2014) over long life spans. In contrast, ruderal strategists have shorter life spans, tend to attain smaller $B$, and dedicate proportionally more NPP to reproduction (Grime \& Pierce, 2012). Stress-tolerant strategists withstand harsh environmental conditions and tend to have low NPP, but span a range of sizes among species (e.g., within the
Cactaceae). Considered together for NPP scaling, high NPP and B are predicted for competitive strategists, whereas stress-tolerants or ruderals should have low NPP across a range of $B$, and intermediate strategists should have intermediate NPP and B (see fig. 1 in Jenkins $\&$ Pierce, 2017). Communities including mixed strategies should also have intermediate NPP and B. These strategies (and intermediates) represent adaptive constraints on metabolic theory based on fractal vascular tissues, and thus predict nonlinear NPP scaling (Figure 1d; Jenkins \& Pierce, 2017).

Consistent with that expectation, NPP scaling is sigmoidal in shape when evaluated from populations to biomes and across wide data ranges (c. 7 and $>5$ orders of magnitude for B and NPP, respectively; see fig. 3 in Jenkins \& Pierce, 2017). Ecosystems NPP scaling was relatively truncated in those analyses (c. 3 orders of magnitude for B) and best represented as a quadratic curve that approached an asymptote (see fig. 2e in Jenkins \& Pierce, 2017). Because that curve fit was placed amidst sigmoidal curves, it was interpreted to support a truncated portion of adaptive life histories strategy theory (Jenkins \& Pierce, 2017) representing especially asymmetric sizebased competition (Kerkhoff \& Enquist, 2006).

\section{4 | Confluence of theory and predictions}

Predator-prey theory, macroecology, and adaptive life history strategies theory (summarized above) converge to provide a framework for analyses of global human impacts on terrestrial plant growth and biomass. Here we evaluate the global human functional response, where we use HANPP as a measure of human consumption in the predator-prey context (i.e., HANPP B; Figure 1e), but also using allometric scaling. Based on the research summarized above, HANPP scaling should approximate a Type I curve (in log-log space). In the two-part predator-prey context, we also evaluate global terrestrial NPP scaling (Figure 1f). Based on the above-described background, global NPP scaling for ecoregions is a strong test of competing predictions about NPP scaling (Figure 1d), where we expect a curvilinear shape in log-log space that supports adaptive life histories strategy theory. To complete the predator-prey context (arrow between Figure 1e,f), we compare totals of each scaling curve (using areas under curves).

We also consider two alternatives to the above approach. We compare potential and actual NPP scaling (i.e., NPP pot $\sim \mathrm{B}_{\text {pot }}$ and $\mathrm{NPP}_{\text {act }} \sim \mathrm{B}_{\text {act }}$ ), where the difference is, by definition, due to human effects on NPP and B. As an alternative, we consider biomass turnover rate ( $T$; per year; Table 1), which is estimated as NPP/B and is thus comparable to a slope coefficient for NPP scaling (i.e., NPP B) used here. Biomass turnover rate (per year) is the inverse of biomass turnover time (year), which is reduced at greater HANPP, with ramifications for the global C budget (Carvalhais et al., 2014; Erb et al., 2016; Friend et al., 2014; Thurner et al., 2017). For example, global terrestrial B turnover time in the year 2000 was half that for natural (potential) conditions, due to human land use (Erb et al., 2016). For biomass turnover rate $(T)$, ecosystems with relatively high NPP and 
low plant B (e.g., grasslands) should naturally have greater $T$ than ecosystems with large plant B (e.g., rain forests). Here we evaluate allometric scaling of $T$ (i.e., $T \sim B$ ) and human effects on $T$ scaling.

\section{5 | Current and future status}

We use data representing the year 2000 (Erb et al., 2018; Haberl et al., 2007). Human population has already increased $24.6 \%$ since 2000 and is expected to increase $59 \%$ by mid-century [i.e., 6.1 billion people in 2000; 7.6 billion in 2019; 9.7 billion by 2050; United Nations, Department of Economic and Social Affairs, Population Division (UN DESA), 2017]. We update results for HANPP as a portion of NPP in year 2000 to current conditions and forecast future conditions. In addition to global population projections, those predictions require per capita HANPP rates (Krausmann et al., 2013). Projections of per capita HANPP rates beyond 2000 here applied two scenarios, based on estimated per capita HANPP estimates from 1910-2005 (Krausmann et al., 2013). The first scenario is pessimistic because it assumes reduction in global per capita HANPP has stagnated, broadly consistent with warnings of limits to human innovation (e.g., Ehrlich, 1968; Ehrlich \& Ehrlich, 1990, 2012, 2013) and summarized as the "prophet" view (Mann, 2018). The second scenario is optimistic because it assumes improved efficiency (i.e., more food and other biomass-derived products delivered to consumers per unit of HANPP due to raised NPP of agro-ecosystems, improved harvest indices and reduced biomass losses in supply chains; Haber et al., 2014) since World War II (WWII) in per capita HANPP will continue, as assumed by Krausmann et al. (2013) and consistent with the "wizard" view (Mann, 2018).

\section{2 | METHODS}

\section{1 | Data sources and processing}

We used publicly available (http://www.aau.at/blog/global-hanpp -2000) HANPP and NPP data representing the year 2000 (Haberl et al., 2007). Potential NPP (NPP ${ }_{\text {pot }}$ ) data represent the hypothetical absence of land use, calculated by the Lund-Potsdam-Jena dynamic global vegetation model (LPJ; Sitch et al., 2003) and developed further to include hydrological and edaphic factors (Haberl et al., 2007). The NPP model thus surpasses some concerns about simpler NPP models that do not account for soil fertility, etc. (Šímová \& Storch, 2017). Like Haberl et al. (2007), we treat potential NPP estimates here as representing natural conditions. Data for the year 2000 are the mean of years 1998-2002 at 5 arc minutes resolution (c. 10-km grids at the equator; Haberl et al., 2007). The HANPP data from Haberl et al. (2007) were based on a variety of sources, including cropland and harvest statistics, LPJ model estimates of actual NPP (NPP ${ }_{\text {act }}$ ), and NPP harvested or destroyed (see Table 1 for definitions). HANPP due to by human-induced fires is not included. The HANPP estimate of Haberl et al. (2007) was calculated as $\mathrm{HANPP}=\mathrm{NPP}_{\text {pot }}-\mathrm{NPP}_{\text {eco }}$, where $\mathrm{NPP}_{\text {eco }}=\mathrm{NPP}_{\text {act }}-\mathrm{HANPP}_{\text {harv }}$ (Table 1; also see Haberl et al., 2014). Both NPP and HANPP data were expressed as $\mathrm{g} \mathrm{C} / \mathrm{m}^{2} /$ year.

Previous analyses compared HANPP to NPP ${ }_{\text {pot }}$ per grid cell (e.g., Haberl et al., 2007). Here we repeat that, but in an allometric scaling context (i.e., HANPP $\sim$ B is compared to $\mathrm{NPP}_{\text {pot }} \sim \mathrm{B}$ ) to combine predator-prey theory and allometric scaling (Figure 1). We also compare $\mathrm{NPP}_{\text {pot }}$ and $\mathrm{NPP}_{\text {act }}$ scaling in the year 2000 as an alternative measure of human effects. Total B (i.e., aboveground + belowground; $\mathrm{g} \mathrm{C} / \mathrm{m}^{2}$ ) data were the independent predictor in NPP and HANPP scaling (obtained from Erb et al. (2018). These B data were a combination of Global Forest Resource Assessment data (Food and Agriculture Organization, 2010) and quantitative estimates for non-forest lands (see Erb et al., 2018 for details). The global B model represented global B patterns well, compared with other models (Erb et al., 2018: extended data Figures 1, 3, 4).

Analyses here use spatially explicit data on HANPP, NPP and B (resolution = 5 arc minutes; Erb et al., 2016, 2018; Haberl et al., 2007). These grid data are robust but spatially autocorrelated (see Supporting Information Figure S1), so we used mean values of ecoregions ( $N=819)$ in analyses. By comparing NPP and HANPP scaling relationships, we also address statistical covariance of each response with $\mathrm{B}$, similar to analyses in finance, where risk and reward are each expressed as a function of company size (e.g., Podobnik, Horvatic, Petersen, \& Stanley, 2009).

The NPP, HANPP and B data sets were generated at $5^{\prime}$ resolution using raster and stack commands (as appropriate to the data set) from the raster package in R (Hijmans, 2019; R Core Team, 2018), which yielded 9,331,200 global grid cells. Terrestrial NPP, HANPP and B data were retained and matched to terrestrial ecoregions, yielding $2,059,206$ grid cells. Allometric scaling analyses use log-transformed axes for reasons explained above (Kerkhoff \& Enquist, 2009), so grid cells with values $=0$ (e.g., in the Sahara Desert) were removed from analyses. This step left $1,778,398$ data values representing $86 \%$ of the global land surface (see Supporting Information Appendix S1 for code and Appendix S2 for data). Mean ecoregion values ( $\pm 1 S D$ ) were calculated from these data to represent 819 of 825 (99\%) of possible terrestrial ecoregions (from https://www.worldwildlife.org/publi cations/terrestrial-ecoregions-of-the-world; Olson et al., 2001) and were used in analyses below.

\section{2 | Analyses}

Local estimation (loess) regressions were used for NPP and HANPP scaling to minimize residual mean square error and provide an efficient, independent test of hypothesized curve shapes (Figure 1) without forcing a priori mathematical functions (e.g., Type I or II predator functional responses). This point warrants emphasis: loess models are useful here for inference precisely because they are 'phenomenological' and free to fit data shape, independent of a priori expectations. Thus, graphical predator-prey theory was evaluated using graphical outcomes to explore the extension of 
locally based ecological theory to global scales. Other regression models may be justified after this work and to provide model parameters not provided by loess fits. Loess regressions use a single predictor (here B). To help understand results, we included mean ecoregion latitude and ecoregion size (number of grid cells) in plots. An optimal span $=0.75$ for local estimation was identified by information theoretic model selection, based on the corrected Akaike information criterion (AICc) and using code at http://grokb ase.com/t/r/r-help/05bhmpgce $5 /$ r-loess-choose-span-to-minim ize-aic.

We evaluated nonlinearity of NPP allometric scaling (in log-log space) by AICc model selection among linear (i.e., $\log _{10}$ NPP $\left.\sim a+b\left(\log _{10} B\right)\right)$, quadratic (i.e., $\log _{10}$ NPP $\sim a+$ $\left.b\left(\log _{10} B\right)-c\left(\log _{10} B\right)^{2}\right)$ and null (i.e., $\log _{10}$ NPPP $\sim 1$ ) models. To be clear, this analysis only evaluated evidence that NPP scaling is linear (per metabolic theory) or nonlinear (per adaptive life history strategies theory). This goal was secondary to the main goals, which were based on loess regression of NPP and HANPP scaling (described above).

The portion of NPP pot appropriated by humans was estimated by

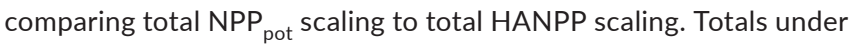
each curve were estimated by integration of the loess curves, where definite integrals of the loess models were calculated and summed over 10,000 intervals. Specifically, the area under each curve segment was estimated as a power function (e.g., NPP $=c B^{m}$ ) between two $B$ values (i.e., $B_{0}$ and $B_{1}$ ):

$$
\int_{\mathrm{B}_{0}}^{\mathrm{B}} \frac{d(\text { NPP or HANPP) }}{d \mathrm{~B}} d \mathrm{~B}=\frac{c * \mathrm{~B}_{0}^{m}}{m+1} *\left[\mathrm{~B}_{1} *\left(\frac{\mathrm{B}_{1}}{\mathrm{~B}_{0}}\right)^{m}-\mathrm{B}_{0}\right]
$$

where $c$ is a constant and $m$ is a coefficient related to rate of increase. Importantly, this integration operated on original (i.e., linear) scales for curves based on log-log axes. Total values of NPP and HANPP scaling curves provided by the integrals were then compared.

As an alternative approach, the log-log NPP pot scaling curve (from above) was compared to the matching curve for $\mathrm{NPP}_{\text {act }}$ (i.e., $\log _{10} \mathrm{NPP}_{\text {act }} \sim \log _{10}$ actual B) where the difference potentially gauges human effects on NPP scaling related to land use. In that analysis, we also expressed each ecoregion's change from NPP to $\mathrm{NPP}_{\text {act }}$ as a vector, where vector length represented displacement in the NPP scaling space. Vector angles informed tipping point estimation, which was conducted with segmented regression (Muggeo, 2008).

Biomass turnover rate $(T)$ was estimated as the NPP/B ratio for both potential and actual conditions. To be consistent with log-log scaling (above), $T$ was calculated as $\log _{10}(\mathrm{NPP})-\log _{10}(\mathrm{~B})$, equivalent to $\log _{10}(\mathrm{NPP} / \mathrm{B})$. Mean values among ecoregions were back-transformed to estimate mean potential $\left(T_{\text {pot }}\right)$ and actual $\left(T_{\text {act }}\right)$ conditions. To help understand variation in $T$, we also computed regressions for $T_{\text {pot }}$ and $T_{\text {act }}$ scaling. Variables to predict potential $T$ included $B_{\text {pot }}$, latitude, climate and a quadratic effect of climate (based on initial plots). Climate was represented by the first axis scores of a principal components analysis (PCA) using annual means and standard deviations of temperature and precipitation per ecoregion, obtained from WorldClim (http://worldclim.org/ bioclim) and matched to grid resolution as above. The PCA axis 1 was loaded by only standard deviation of annual temperature (loading $=-0.58$ ) and annual mean precipitation (loading $=0.81$ ), and represented $80.9 \%$ of variation in climate variables. Alternative models ( $B_{\text {pot }}$, climate or both) as predictors of $T_{\text {pot }}$ were evaluated by AICc weight $\left(w_{i}\right)$, as above.

The full model for $T_{\text {act }}$ was similar to that for $T_{\text {pot }}$, but used $B_{\text {act }}$ instead of $B_{\text {pot }}$ and included $\log _{10}$ (human population size) and $\log _{10}$ (HANPP) as additional predictors. Alternative models were again compared by AICc $w_{i}$. Human population data (Center for International Earth Science Information Network, 2018) were matched to NPP data in resolution and projection and predict well economy and resource consumption (Zhang \& Yu, 2010).

\section{3 | Projections}

Recent (2019) and future (2050) HANPP were projected as \% of NPP, based on medium-variant population projections (UN DESA, 2017) and estimates of global per capita HANPP, which declined from 1910 to 2005 (Krausmann et al., 2013). Two scenarios were modelled for per capita HANPP trends. First, per capita HANPP trend data for 1910-2005 (Krausmann et al., 2013) were statistically modelled, which assumes conditions driving global HANPP were consistent throughout the 20th century. Second, 1950-2005 data were modelled because the decline in per capita HANPP started c. 1950, roughly coinciding with global changes in agriculture and economic development post-WWII (Mann, 2018). This second scenario assumes conditions driving global HANPP shifted substantially after WWII (Mann, 2018). Projection from either scenario ignores potential effects of other future processes (e.g., climate change, soil erosion, migration, etc.) and assumes that global potential NPP scaling on land is unchanged (Running, 2012). Projections here differ from those of Krausmann et al. (2013) because: (a) we used statistical model selection to fit two alternative regressions, whereas they applied an exponential model, and (b) their scenarios focused on bioenergy production, whereas ours are more general.

For each per capita HANPP scenario, alternative models (null, linear, quadratic and sigmoidal) were compared by AICc weights, and the most plausible model selected. The sigmoidal function used a four-parameter cumulative Weibull function in the drc package of $R$ (Ritz, Baty, Streibig, \& Gerhard, 2015). Each scenario's most-plausible model was then used to calculate the percent change in per capita HANPP from year 2000, and to project to 2019 and 2050 using the product of per capita HANPP and estimated global population. If per capita HANPP stabilizes (pessimistic scenario), then HANPP/ NPP will be driven by population growth. However, decreasing per capita HANPP (optimistic scenario) will mitigate population growth effects on HANPP. 


\section{3 | RESULTS}

\section{1 | Human appropriation of net primary production}

Global HANPP scaling was well described by the loess model (Figure 2), as evidenced by the narrow confidence intervals and plot of residuals (see Supporting Information Figure S2). The location of ecoregions in the trend was influenced by latitude (Figure 2), with a decline at highest $B$ representing as-yet unharvested tropical forests. Isopleths for data density in Figure 2 show that many ecoregions with relatively high $\mathrm{B}\left(\sim 10^{4} \mathrm{gC} / \mathrm{m}^{2}\right)$ have relatively high HANPP $\left(\sim 10^{2} \mathrm{~g} \mathrm{C} / \mathrm{m}^{2} /\right.$ year), though that ratio varies by about one order of magnitude. The shape of HANPP scaling is similar to a Type I predator functional response in log-log allometric space (Figure 2), or roughly a Type II curve in linear space. Thus, human "consumption" increases proportionally with the amount of plant $B$ in an ecoregion. This result is consistent with the finding (below) that humans are a driver of global terrestrial plant biomass turnover rate $T$.

\section{2 | NPP scaling}

The loess models for potential and actual NPP scaling (Figure 3a,b, respectively) indicated curvature, contrary to expectations of metabolic theory but in support of adaptive life histories strategy. Consistent with a curved scaling pattern, segmented regression

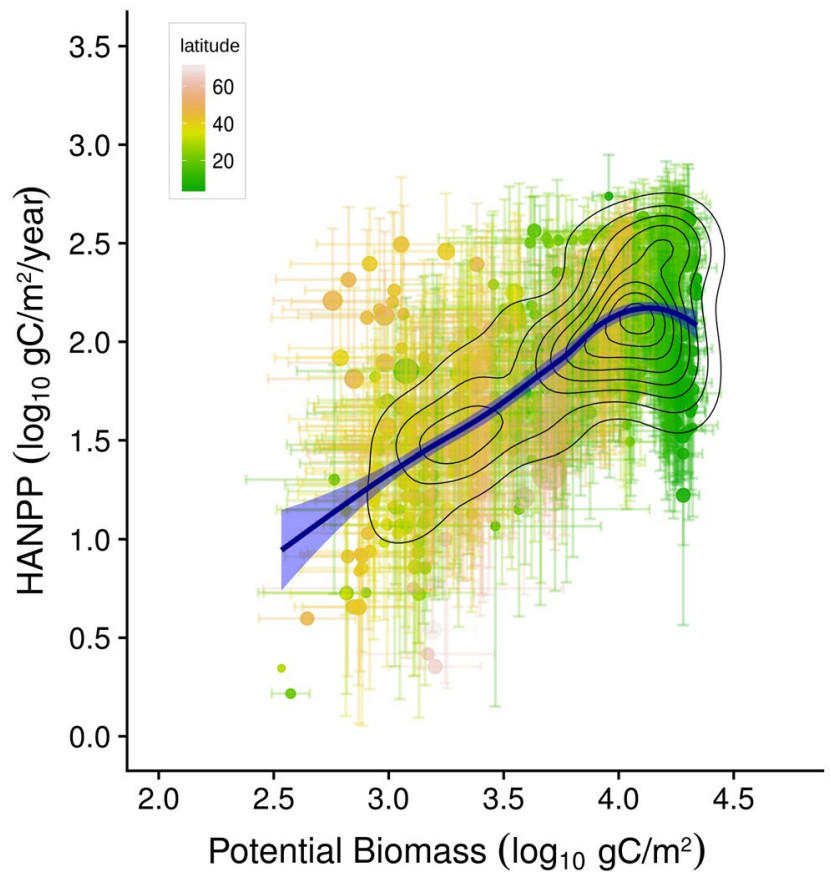

FIGURE 2 Allometric scaling of human appropriation of net primary production (HANPP) as a function of potential plant biomass (B), using logarithmic scales. Line represents local estimation of ecoregion means; isopleths represent data density. $N=819$ [Colour figure can be viewed at wileyonlinelibrary.com] detected a break point for $\mathrm{NPP}_{\text {pot }}$ at $\log _{10}\left(\mathrm{~B}_{\text {pot }}\right)=3.16 \mathrm{~B}_{\text {pot }} \pm 0.07$ (95\% confidence interval), with a greater slope $(1.19 \pm 0.17)$ on the left of the break point than on the right $(0.51 \pm 0.03$; Figure $3 b)$. The tipping point for NPP act $\left(2.94 \mathrm{~B}_{\text {act }} \pm 0.05\right)$ was slightly lower than that for $\mathrm{NPP}_{\text {pot }}$ with slightly greater slopes (left; $1.68 \pm 0.27$ : right; $0.60 \pm 0.03$; Figure $3 b$ ). Plant biomass was changed more than NPP between potential and actual (year 2000) conditions, especially in ecoregions with greater $\mathrm{B}$, as shown by vectors of change
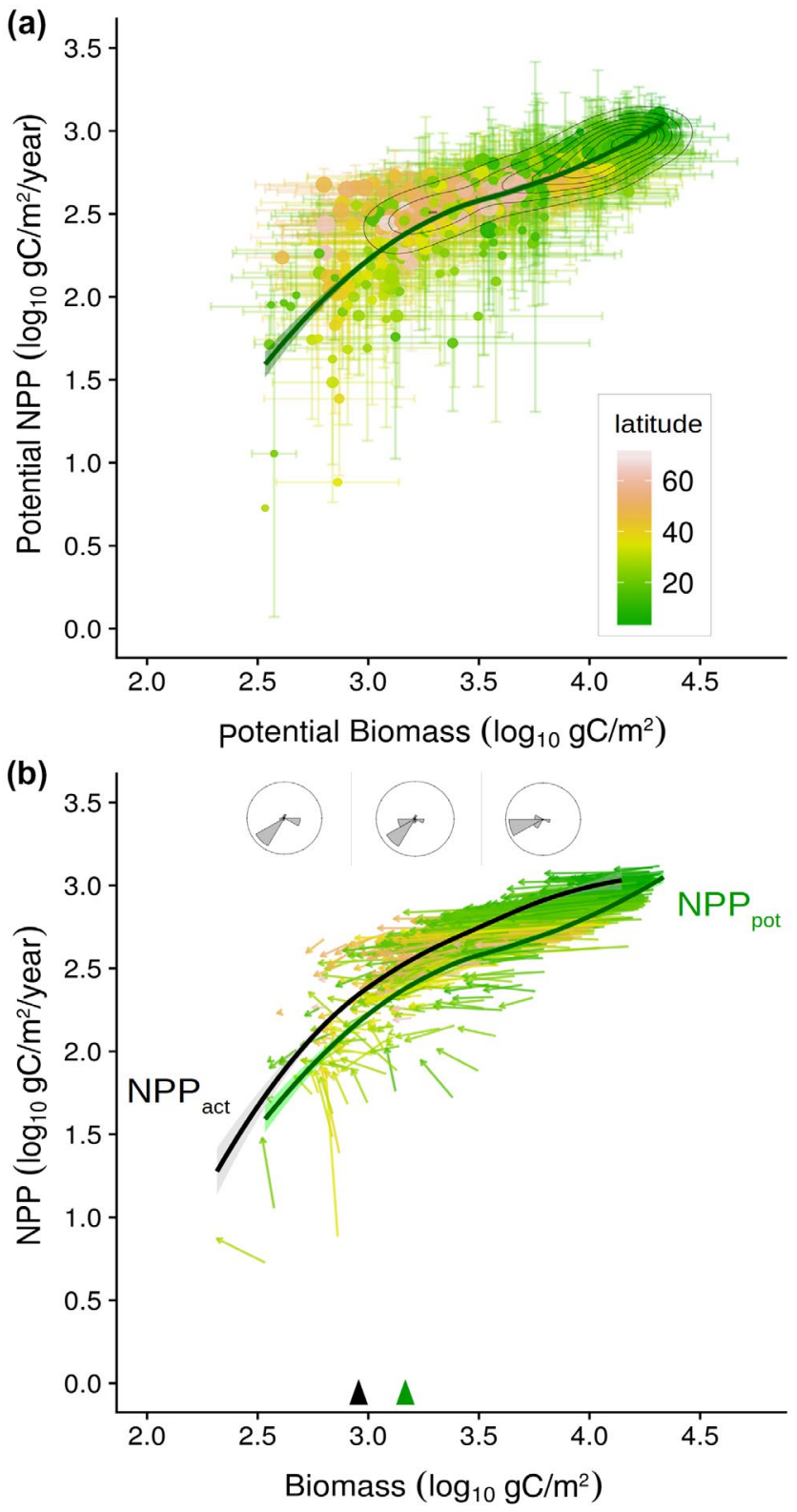

FIGURE 3 Terrestrial net primary production (NPP) scaling. (a) Allometric scaling of potential NPP (i.e., NPP ${ }_{\text {pot }}$ ) as a function of potential biomass $\left(\mathrm{B}_{\text {pot }}\right)$, using logarithmic scales. Line represents local estimation of ecoregion means; isopleths represent data density. (b) NPP ${ }_{\text {pot }}$ and actual NPP (NPP ${ }_{\text {act }}$ ) as function of current actual biomass $\left(\mathrm{B}_{\mathrm{act}}\right)$, where change in each ecoregion is depicted with a vector (arrows). Rosette plots (top) depict angles of vectors within marked zones, and triangles (bottom) show tipping points for each scaling function. $N=819$ [Colour figure can be viewed at wileyonlinelibrary.com] 
(Figure $3 b$ ). These changes drove the $\mathrm{NPP}_{\text {act }}$ curve primarily to the left of the NPP ${ }_{\text {pot }}$ curve, while maintaining a similar shape within the general trajectory.

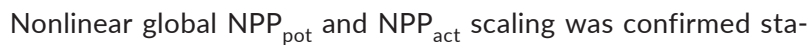
tistically, where a quadratic model was more plausible than a linear model in both cases (AICc $\left.w_{i}=1.0\right) ; w_{i}<.001$ for a linear model in log-log space, as predicted by metabolic theory. Also, residuals of logarithmic scaling relationships (see Supporting Information Figure S2) fit statistical assumptions better than linear scaling models (as expected). To be clear, the quadratic model was used only to statistically evaluate NPP scaling curvature and was not used in figures here. (a)

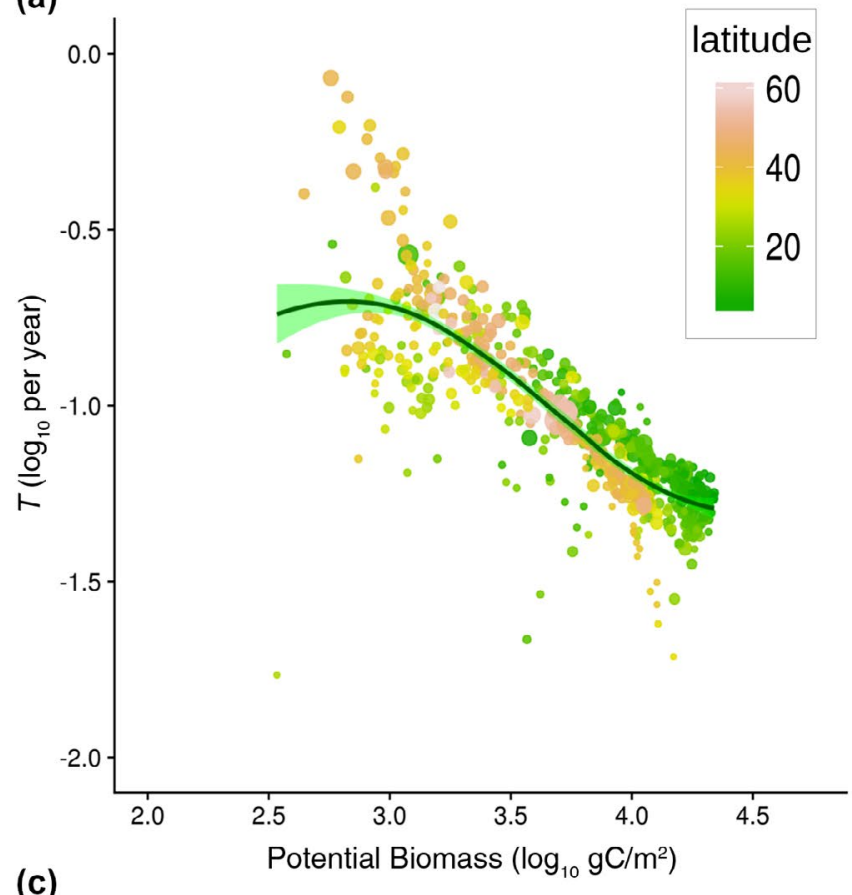

(c)

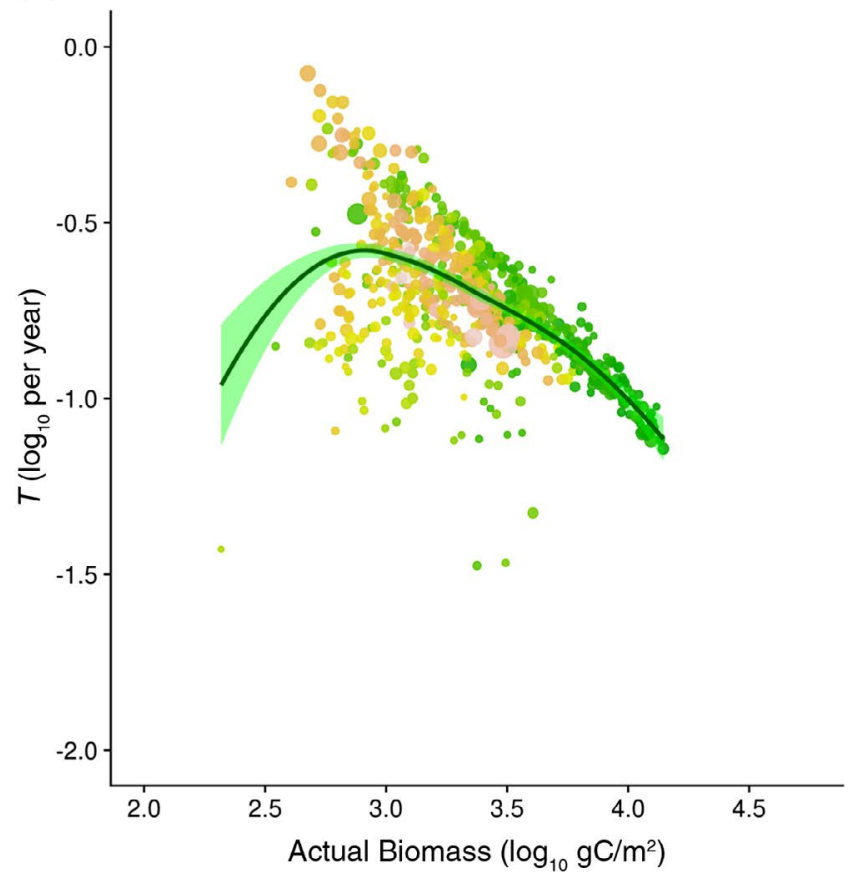

(b)

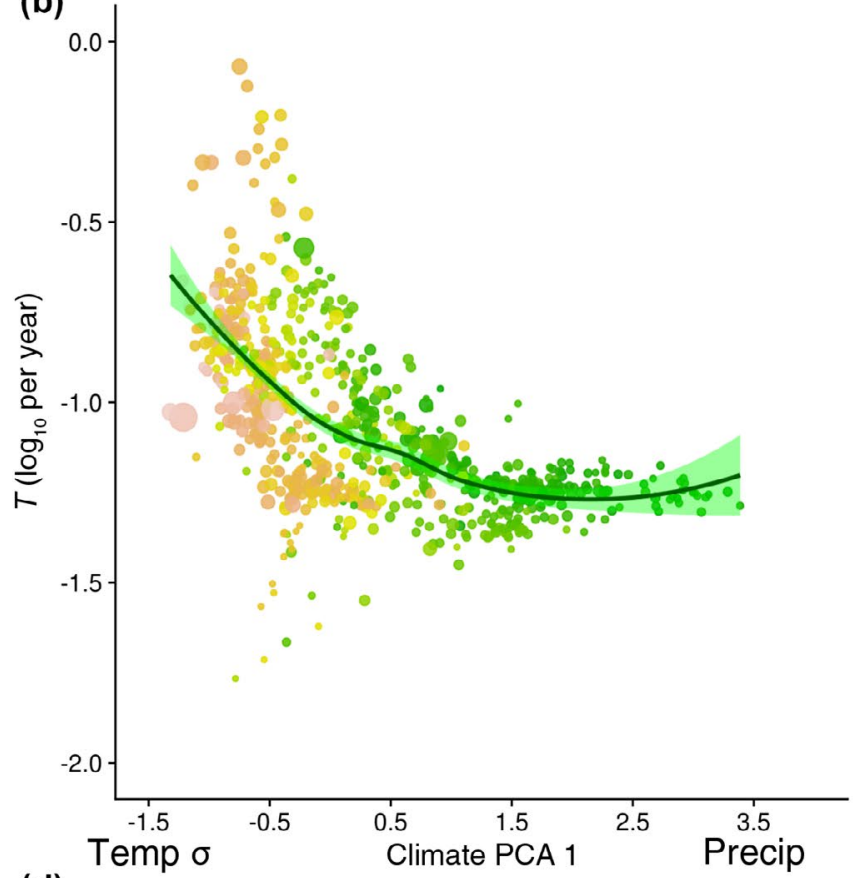

(d)

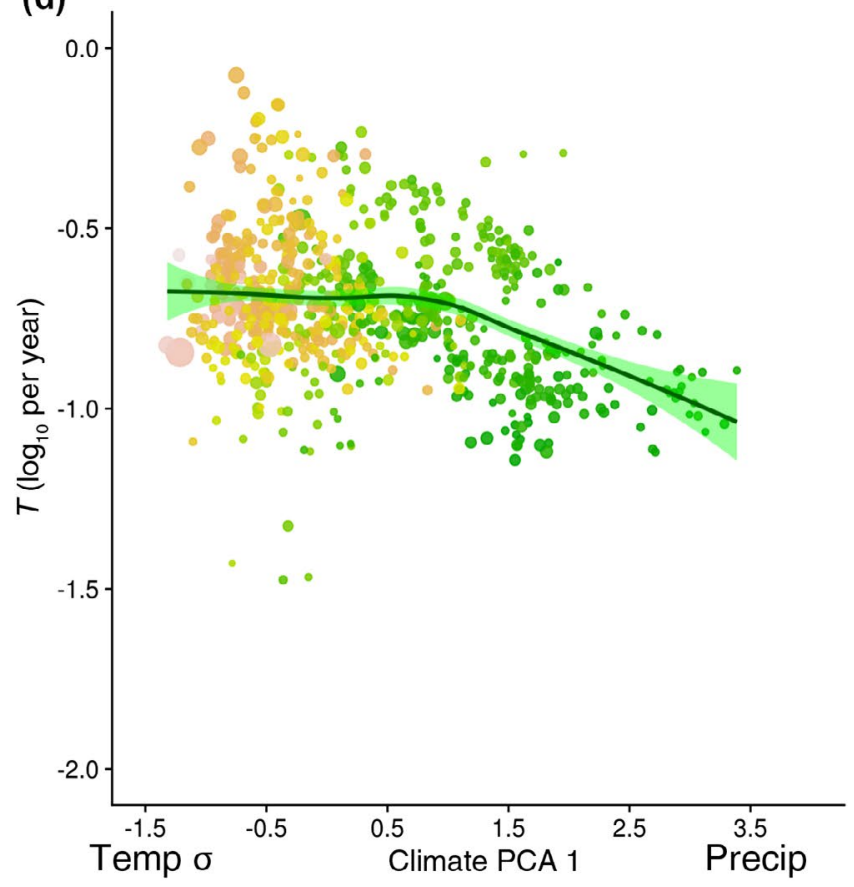

FIGURE 4 Potential and actual biomass turnover rate $(T)$ scaling as a function of plant biomass (B) and as a function of climate. (a) Potential $T \sim$ potential B. (b) Potential $T$ is predicted well by climate [i.e., principal components axis 1 (PCA 1), representing annual mean temperature and annual mean precipitation standard deviations; $80 \%$ of variation in global climate variables]. (c) Actual $T$ (year 2000 ) is less predictably a function of actual $B$ than in (a). (d) Actual $T$ is less predictably a function of the same climate conditions as in (b). Human appropriation of net primary production (HANPP) is also required in the local estimation regression model to match the fit of (b) above (please see text for regression details). $N=819$ [Colour figure can be viewed at wileyonlinelibrary.com] 


\subsection{HANPP as a portion of NPP}

Comparison of definite integrals for the HANPP and NPP $_{\text {pot }}$ scaling models (Figures 2 and 3a) represented a "predator-prey" comparison that estimated global total HANPP in the year 2000 was about $16.4 \%$ of global terrestrial NPP pot . This regression-based value was slightly less than an estimate (22.1\%) based on summed HANPP and $\mathrm{NPP}_{\text {pot }}$ across ecoregions and made similar to prior empirical estimates of gridded data. Like any regression, results here do not fully represent all variation among ecoregions (see scatter in Figures 2 and $3 a$ ), suggesting scatter in the regressions of ecoregion means (Figures 2 and $3 a$ ) accounted for the $6 \%$ underestimate. We refer to both the 16 and $22 \%$ estimates for projections to current and future conditions, below.

\subsection{Biomass turnover rate $(T)$}

Greater change in B (i.e., $B_{\text {pot }}-B_{\text {act }}$ ) than in NPP (i.e., NPP pot $-\mathrm{NPP}_{\text {act }}$ ) is consistent with accelerated biomass turnover rates $(T)$. In the year 2000, geometric mean $T_{\text {act }}=0.191 /$ year, which was 2.25 -fold $T_{\text {pot }}$ (0.084/year). This change was statistically significant by $t$ test $(p<.001)$. Scaling relationships (i.e., $T \sim$ B) were predictive and informative. For potential (i.e., natural) conditions, greater $T_{\text {pot }}$ occurred in low-B ecoregions at higher seasonal latitudes (Figure 4a,b). As a result, $\log _{10}\left(T_{\text {pot }}\right)$ was predicted most plausibly (AICC $w_{i}=1.0$, next $\triangle \mathrm{AICc}=61.4)$ by $\mathrm{B}$ and climate $\left[\log _{10} T_{\text {pot }}=1.164-0.594 *\right.$ $\log _{10}\left(\mathrm{~B}_{\text {pot }}\right)+0.080 *$ climate -0.011 climate $^{2}$; adjusted $R^{2}=.73$; residual standard error $(\mathrm{RSE})=0.123, d f=800]$. Thus, $T_{\text {pot }}$ in former, natural conditions was largely a function of plant biomass and climate.

In the year 2000, comparably predictive modelling of biomass turnover $\left(T_{\text {act }}\right)$ requires human population and HANPP. Compared to $T_{\text {pot }}$ scaling, $T_{\text {act }}$ scaling was relatively elevated but less clearly linear (compare Figure $4 \mathrm{a}, \mathrm{c}$ ), and less clearly a function of climate (compare Figure $4 \mathrm{~b}, \mathrm{~d}$ ). Adjusted $R^{2}$ was only .51 for $T_{\text {act }}=B_{\text {act }}+$ climate (i.e., same structure as the $T_{\text {pot }}$ model above). However, including human population size and HANPP as predictors greatly improved the model again and made it far more plausible (AICc $w_{i}=1.0$, next $\Delta$ AICc $=31.4)$. The model $\left[T_{\text {act }}=0.557-0.537^{*} \log _{10}\left(B_{\text {act }}\right)+0.021 *\right.$ climate $-0.009 *$ climate $^{2}-0.036 *{ }^{*} \log _{10}$ (population) $+0.309 *$ $\log _{10}\left(\right.$ HANPP)] was about as predictive as the $T_{\text {pot }}$ model (adjusted $R^{2}=.72$, RSE $=0.100, d f=798$ ). Based on this model, an increase in population size slightly reduces $T_{\text {act }}$, but an increase in HANPP increases $T_{\text {act }}$.

\section{5 | Projections}

Two scenarios were projected for current and future HANPP relative to NPP. For the pessimistic scenario, 1910-2005 per capita HANPP was most plausibly modelled (AICc $w_{i}=.95$, next $\Delta \mathrm{AICc}=6.4$ ) by a sigmoidal function that approaches a lower asymptote (i.e., stagnating efficiency): per capita HANPP $=2.014+(3.364-2.014)$ * $\exp \left(-\exp \left(86.212^{*}(\log (\right.\right.$ year $\left.\left.)-\log (1976.7))\right)\right) ; \operatorname{RSE}=0.056,5 d f$, all terms $p<.005$. This model predicted per capita HANPP stabilized to a lower asymptote (43.5\% reduction in both 2019 and 2050). By this scenario, the $c$. 7.6 billion people inhabiting this planet in 2019 have increased HANPP scaling from 16-22\% in the year 2000 to $20-28 \%$ of potential NPP in the year 2019. By the same scenario, human population growth ( 9.7 billion by 2050 ) will push HANPP to $25-35 \%$ of potential NPP by mid-century.

For the optimistic scenario, post-WWII per capita HANPP was most plausibly fit by a quadratic model that declined at a slowing rate through time: per capita HANPP $=53.9$ $0.5351^{*}$ (year) + 0.0001296*(year^2); $\mathrm{AICC}_{i}=.72$, next $\Delta \mathrm{AICC}=2.8$, $\mathrm{RSE}=0.028,4 d f$, adjusted $R^{2}=.996$, all terms $p \leq .025$. Extrapolating this model to 2019 and 2050 predicts that per capita HANPP continues to become more efficient (48 and 55\% reductions from 1910, respectively). Using the same population projections as above, this second scenario predicts that 2019 HANPP $=18-24 \%$ of potential NPP, and that in 2050 HANPP will be $20-26 \%$ of potential NPP. If continued, decreasing per capita HANPP (i.e., increasing per capita HANPP efficiency) since 1950 will greatly mitigate effects of projected global human population growth, represented as HANPP.

\section{4 | DISCUSSION}

Global human impacts on natural systems have been considered for decades, with a prominent quantitative estimate being HANPP. We found that ecological theory helps to understand global relationships between HANPP, terrestrial plant growth (NPP) and biomass (B). Empirically based knowledge that human population growth and resource use efficiency are globally important is now backed by evidence gathered in the context of ecological theory. Results here also indicate that global carbon budgets need to include both top-down and bottom-up regulators to be more accurate.

In principle, ecological theory should help inform sustainability science's efforts to understand and mitigate human impacts. In practice, this linkage occurs rarely, perhaps related to challenges in scaling up expectations derived from local ecology. Here we linked three otherwise disparate ecological theories to estimates of global human impacts on terrestrial plants. Until this work, graphical predator-prey theory (i.e., theory based on May, 1977; Noy-Meir, 1975) had not been related to allometric scaling used in macroecology, though it was recently anticipated (Jenkins \& Pierce, 2017). A foundation existed as NPP scaling (e.g., Enquist, West, \& Brown, 2009; Jenkins, 2015; West, Enquist, \& Brown, 2009), which represents the prey half of predator-prey scaling. The other half (HANPP scaling) was novel here, as was its comparison to NPP scaling. Global HANPP and NPP scaling demonstrated the general predictive capability of macroecological allometric scaling at the greatest possible extent. The shape of scaling curves was also linked to theory, where adaptive life history strategies theory (Grime \& Pierce, 2012) was supported as a driver of global NPP 
scaling, consistent with other results for ecosystems (Jenkins \& Pierce, 2017), and instead of metabolic theory (Brown et al., 2004; Enquist et al., 1998; West et al., 1999). Results for NPP scaling of 107 ecosystems gleaned from the literature (in Jenkins \& Pierce, 2017) and 819 ecoregions here greatly overlapped, with similar extents in both axes. Much like results for ecosystems reported by Jenkins and Pierce (2017), NPP scaling for ecoregions here represented but a segment of a broader possible curve. Data for subsets of ecosystems (i.e., populations and assemblages; Jenkins \& Pierce, 2017) may be needed to contribute to the lower tail of a sigmoidal NPP scaling curve (i.e., low B and low NPP) because integrative data at greater spatial scales for ecosystems and ecoregions do not approach those lower values. This result indicates that metabolic theory is scale-dependent; it can work well for local scales (e.g., individual plants, plots, forest stands), but widely different adaptive life history strategies must also be considered across greater scales (Grime \& Pierce, 2012; Jenkins \& Pierce, 2017).

Analyses here estimate global human "predation" on plants in three ways: HANPP scaling as a portion of NPP scaling, changes in NPP scaling, and biomass turnover rate T. HANPP scaling as a portion of NPP scaling and $T$ were more sensitive measures of human impact than was comparison of potential and actual NPP scaling. This occurred because B was more strongly affected by land use than NPP, consistent with Erb et al. (2016). As a result, T scaling in the year 2000 was less a function of climate (as in natural conditions) and more a function of human impacts.

The predator-prey approach used here supports prior work (Haberl et al., 2007) but does not replace those detailed estimates, which more directly relate to global $\mathrm{C}$ budgets. Instead, it serves as a basis for future statistical models to better represent residual variation and perhaps more closely approach empirical estimates. Scaling models for HANPP, NPP and T do not perfectly represent the bivariate patterns, and scatter around the regression models represents a potentially rich direction for future research. For example, HANPP is affected by socioeconomic phenomena, which should alter allometric relationships expected based on natural laws alone (Marques et al., 2019). Also, wide variation in HANPP scaling at high $B\left(>10^{4} \mathrm{~g} / \mathrm{m}^{2}\right.$; Figure 2) may represent historical legacies and recent human land use on tropical deforestation (Sponsel et al., 1996). Going forward, this variation may collapse without rapid implementation of better strategies for sustainable land use in the tropics (DeFries \& Rosenzweig, 2010). If so, then ongoing destruction of tropical forests will more closely conform with the linear (unsatiated) HANPP scaling at $B<10^{4} \mathrm{~g} / \mathrm{m}^{2}$, which would represent vast and deep human effects on this global $C$ component and its biodiversity. Thus, changes in HANPP scaling variance may be a sensitive summary measure of future land use impacts in a globalized economy.

For regional human populations, NPP and HANPP scaling alone represent but one potential limit to population growth, and ongoing changes may raise or reduce those limits (d'Amour et al., 2017; Lobell, Schlenker, \& Costa-Roberts, 2011). Given its apparent sensitivity to human land use, biomass turnover rate $(T)$ or its inverse (Erb et al., 2016) should be more prominent in further analyses and projections of human impacts and reciprocal effects of natural resource limits on sustainable human population size.

Going forward, the two scenarios projected here represent "optimistic" and "pessimistic" levels of HANPP scaling, where a 59\% increase in human population from 2000 to 2050 (UN DESA 2017) would cause HANPP to increase either $20-28$ or $25-35 \%$. A choice between the two scenarios hinges on global conditions before and after WWII. The optimistic ("wizardly"; Mann, 2018) scenario was based on conditions after WWII, when per capita HANPP decreased during the "green revolution" (Borlaug, 2007; Khush, 1999). Continuation of this trend essentially expects that advancing technologies will partially continue to improve HANPP efficiency and reduce counterproductive side effects (e.g., Appels et al., 2018; Van Deynze et al., 2018). Alternatively, the pessimistic ("prophetic"; Mann, 2018) projection here used pre- and post-WWII per capita HANPP data (Krausmann et al., 2013), and indicated that per capita HANPP efficiency has stagnated. In this case, global HANPP will increase proportionally with human population size and is consistent with decades of forewarnings (e.g., Brown et al., 2014; Ehrlich, 1968; Ehrlich \& Ehrlich, 1990, 2012, 2013; Foley et al., 2005). We conclude that substantial, rapid gains in HANPP efficiency are needed to stabilize HANPP and conserve natural vegetation during expected human population growth (Wilson, 2017). For example, agricultural yields could be increased in regions yielding less than their potential (Tilman et al., 2011), though regional effects (e.g., downstream eutrophication) must also be mitigated (Mueller et al., 2012). So far, agricultural yields are not increasing fast enough (Ray, Mueller, West, \& Foley, 2013). Other opportunities to increase both overall HANPP efficiency and $C$ uptake exist in forest conservation and management, especially in tropical forests where high NPP and B coincide and where much biodiversity exists (Bastin et al., 2019; Erb et al., 2018; Marques et al., 2019).

Unfortunately, global T (via harvest, burning, etc.) is now twice its potential natural value and likely to accelerate with human population growth and resource use. Thus, greater NPP alone cannot provide sufficient $C$ sink because grown biomass is also increasingly depleted, and efforts to predict or understand $T$ without accounting for human effects (e.g., Carvalhais et al., 2014) remain incomplete. This is especially so in tropical regions where $T_{\text {act }}$ has increased relative to potential natural conditions (compare Figure 4b,d). Large-scale, coordinated efforts in two related themes are essential to the near-term human future: (a) to generally improve HANPP efficiency in agriculture, food supply, timber, construction engineering and urban planning (e.g., Dahlbo et al., 2015; Hunter, Smith, Schipanski, Atwood, \& Mortensen, 2017; Kummu et al., 2012; Marques et al., 2019; Sikkema, Dallemand, Matos, Velde, \& San-Miguel-Ayanz, 2017); and (b) to educate people about this broad subject, including greater access by women to education and family planning (Lutz \& Samir, 2011). As a quantitative measure of our collective impact, HANPP and T emphasize that plants are fundamental for all human populations, more so than mined resources sometimes used to evaluate limits to human population growth (Brown et al., 2014; Meadows et al., 1972; 
Sabin, 2013). Human impacts on vegetation should be included in projections of resource shortages in coming decades (e.g., United Nations World Water Assessment Programme, 2018), recommendations of the Intergovernmental Science-Policy Platform on Biodiversity and Ecosystem Services (http://www.ipbes.net) and others (e.g., Ehrlich \& Ehrlich, 2012, 2013), and actions to address those challenges, such as the UN Sustainable Development Goals (http://www.un.org/sustainabledevelopment).

\section{5 | CONCLUSIONS}

The confluence of graphical predator-prey theory, macroecological allometric scaling, and adaptive strategies theory applied here to HANPP, NPP and B broadly supported empirical estimates and enabled novel insights. Graphical predator-prey theory is updated and extended to work globally here using logarithmic scaling of HANPP and NPP as functions of plant B. Adaptive strategies theory (rather than metabolic theory) is supported by the NPP scaling curve. Plant biomass is more sensitive to human land use than is NPP, and human effects are now required to adequately predict biomass turnover rate $(T)$. Human population growth and per capita HANPP efficiency strongly affect terrestrial plant NPP and $B$, and thus global biodiversity and carbon budgets. Scientific estimates of global biodiversity and carbon budgets may be improved by including human population growth and per capita HANPP efficiency. Science-based policies are fully justified where aimed to humanely slow human population growth (e.g., greater access by women to education and family planning) and enhance HANPP efficiency (e.g., more solar and wind energy rather than wood fuels, engineered building materials and packaging to reduce lumber and fibre use, reduced food waste, sustainably increased agricultural intensity).

\section{ACKNOWLEDGMENTS}

DGJ thanks Lisa McCauley for help with GIS in R, the UCF $D^{4}$ lab (sciences.ucf.edu/biology/d4lab) for helpful conversations and edits, Irene Šímová for careful editing, and the Ying Family Foundation for continuing support. K-HE acknowledges funding from the German Research Foundation project no. KA 4815/1-1 (Cobaluce). HH acknowledges funding from the Austrian Science Fund (FWF), project no. P29130-G27 (GELUC). K-HE and HH acknowledge funding from the Vienna Science and Technology Fund (WWTF), project ESR17014 (Vienna's Global Biodiversity Footprint). Dedicated to Bryce Lederer, in hope of a sustainable future for his generation.

\section{DATA AVAILABILITY STATEMENT}

Original HANPP and NPP data are available at http://www.aau.at/ blog/global-hanpp-2000 (Haberl et al., 2007). Plant biomass data were reported in Erb et al. (2018). Other resources (ecoregions, climate data) used here are also publicly available and listed. Analytical $\mathrm{R}$ code and compiled data representing the year 2000 per ecoregion
( $N=819$; per Olson et al., 2001) for NPP, HANPP, B and used here for analyses are available in the Supporting Information Appendices S1 and S2.

\section{ORCID}

David G. Jenkins (iD https://orcid.org/0000-0002-0363-2260

Helmut Haberl iD https://orcid.org/0000-0003-2104-5446

\section{REFERENCES}

Appels, R., Eversole, K., Stein, N., Feuillet, C., Keller, B., Rogers, J., ... Wang, L. E. (2018). Shifting the limits in wheat research and breeding using a fully annotated reference genome. Science, 361(6403), eaar7191.

Bar-On, Y. M., Phillips, R., \& Milo, R. (2018). The biomass distribution on Earth. Proceedings of the National Academy of Sciences USA, 115(25), 6506-6511.

Barnosky, A. D., Hadly, E. A., Bascompte, J., Berlow, E. L., Brown, J. H., Fortelius, M., ... Martinez, N. D. (2012). Approaching a state shift in Earth's biosphere. Nature, 486(7401), 52-58.

Bastin, J.-F., Finegold, Y., Garcia, C., Mollicone, D., Rezende, M., Routh, D., ... Crowther, T. W. (2019). The global tree restoration potential. Science, 365(6448), 76-79.

Beisner, B. E., Haydon, D. T., \& Cuddington, K. (2003). Alternative stable states in ecology. Frontiers in Ecology and the Environment, 1(7), 376-382.

Borlaug, N. E. (2007). Sixty-two years of fighting hunger: Personal recollections. Euphytica, 157(3), 287-297.

Brown, J. H. (1995). Macroecology. Chicago, IL: University of Chicago Press.

Brown, J. H., Burger, J. R., Burnside, W. R., Chang, M., Davidson, A. D., Fristoe, T. S., ... Okie, J. G. (2014). Macroecology meets macroeconomics: Resource scarcity and global sustainability. Ecological Engineering, 65, 24-32.

Brown, J. H., Gillooly, J. F., Allen, A. P., Savage, V. M., \& West, G. B. (2004). Toward a metabolic theory of ecology. Ecology, 85(7), 1771-1789.

Carvalhais, N., Forkel, M., Khomik, M., Bellarby, J., Jung, M., Migliavacca, M., ... Weber, U. (2014). Global covariation of carbon turnover times with climate in terrestrial ecosystems. Nature, 514(7521), 213-217.

Center for International Earth Science Information Network. (2018). Gridded population of the world, v. 4 (GPWv4): Population count, revision 11. Palisades, NY: NASA Socioeconomic Data and Applications Center, Columbia University. https://doi.org/10.7927/H4JW8BX5

Chatham House. (2018). Resourcetrade.earth. Retrieved from http:// resourcetrade.earth

Dahlbo, H., Bachér, J., Lähtinen, K., Jouttijärvi, T., Suoheimo, P., Mattila, T., ... Saramäki, K. (2015). Construction and demolition waste management-A holistic evaluation of environmental performance. Journal of Cleaner Production, 107, 333-341.

d'Amour, C. B., Reitsma, F., Baiocchi, G., Barthel, S., Güneralp, B., Erb, K.-H., ... Seto, K. C. (2017). Future urban land expansion and implications for global croplands. Proceedings of the National Academy of Sciences USA, 114(34), 8939-8944.

Darimont, C. T., Fox, C. H., Bryan, H. M., \& Reimchen, T. E. (2015). The unique ecology of human predators. Science, 349(6250), 858-860.

DeFries, R., \& Rosenzweig, C. (2010). Toward a whole-landscape approach for sustainable land use in the tropics. Proceedings of the National Academy of Sciences USA, 107(46), 19627-19632.

Ehrlich, P. R. (1968). The population bomb. New York, NY: Ballantine.

Ehrlich, P. R., \& Ehrlich, A. H. (1990). The population explosion. New York, NY: Touchstone Books.

Ehrlich, P. R., \& Ehrlich, A. H. (2012). Solving the human predicament. International Journal of Environmental Studies, 69(4), 557-565. 
Ehrlich, P. R., \& Ehrlich, A. H. (2013). Can a collapse of global civilization be avoided? Proceedings of the Royal Society B: Biological Sciences, 280(1754), 20122845.

Ellis, E. C., Kaplan, J. O., Fuller, D. Q., Vavrus, S., Goldewijk, K. K., \& Verburg, P. H. (2013). Used planet: A global history. Proceedings of the National Academy of Sciences of the United States of America, 110(20), 7978-7985.

Enquist, B. J., Brown, J. H., \& West, G. B. (1998). Allometric scaling of plant energetics and population density. Nature, 395(6698), 163-165.

Enquist, B. J., West, G. B., \& Brown, J. H. (2009). Extensions and evaluations of a general quantitative theory of forest structure and dynamics. Proceedings of the National Academy of Sciences of the United States of America, 106(17), 7046-7051.

Erb, K.-H., Fetzel, T., Plutzar, C., Kastner, T., Lauk, C., Mayer, A., ... Haberl, H. (2016). Biomass turnover time in terrestrial ecosystems halved by land use. Nature Geoscience, 9(9), 674-678.

Erb, K. H., Kastner, T., Plutzar, C., Bais, A. L. S., Carvalhais, N., Fetzel, T. ... Pongratz, J. (2018). Unexpectedly large impact of forest management and grazing on global vegetation biomass. Nature, 553(7686), 73-76.

Foley, J. A., DeFries, R., Asner, G. P., Barford, C., Bonan, G., Carpenter, S. R., ... Helkowski, J. H. (2005). Global consequences of land use. Science, 309(5734), 570-574.

Food and Agriculture Organization. (2010). Global forest resources assessment. Main Report, FAO Forestry Paper 163. Rome, Italy: Author

Friend, A. D., Lucht, W., Rademacher, T. T., Keribin, R., Betts, R., Cadule, P., ... Ito, A. (2014). Carbon residence time dominates uncertainty in terrestrial vegetation responses to future climate and atmospheric $\mathrm{CO}_{2}$. Proceedings of the National Academy of Sciences of the United States of America, 111(9), 3280-3285.

Grime, J. P., \& Pierce, S. (2012). The evolutionary strategies that shape ecosystems. Chichester, UK: Wiley-Blackwell.

Haberl, H., Erb, K. H., \& Krausmann, F. (2014). Human appropriation of net primary production: Patterns, trends, and planetary boundaries. Annual Review of Environment and Resources, 39, 363-391.

Haberl, H., Erb, K. H., Krausmann, F., Gaube, V., Bondeau, A., Plutzar, C., ... Fischer-Kowalski, M. (2007). Quantifying and mapping the human appropriation of net primary production in earth's terrestrial ecosystems. Proceedings of the National Academy of Sciences of the United States of America, 104(31), 12942-12947.

Hijmans, R. J. (2019). Raster: Geographic data analysis and modeling. R package version 2.8-19. Retrieved from https://CRAN.R-project.org/ package $=$ raster

Holling, C. S. (1959). The components of predation as revealed by a study of small-mammal predation of the European pine sawfly. Canadian Entomologist, 91(5), 293-320.

Hunter, M. C., Smith, R. G., Schipanski, M. E., Atwood, L. W., \& Mortensen, D. A. (2017). Agriculture in 2050: Recalibrating targets for sustainable intensification. BioScience, 67(4), 386-391.

Imhoff, M. L., Bounoua, L., Ricketts, T., Loucks, C., Harriss, R., \& Lawrence, W. T. (2004). Global patterns in human consumption of net primary production. Nature, 429(6994), 870-873.

Jenkins, D. G. (2015). Estimating ecological production from biomass. Ecosphere, 6(4), 1-31.

Jenkins, D. G., \& Pierce, S. (2017). General allometric scaling of net primary production agrees with plant adaptive strategy theory and has tipping points. Journal of Ecology, 105(4), 1094-1104.

Kahlert, J., Fox, A. D., Heldbjerg, H., Asferg, T., \& Sunde, P. (2015). Functional responses of human hunters to their prey-Why harvest statistics may not always reflect changes in prey population abundance. Wildlife Biology, 21(6), 294-303.

Kerkhoff, A. J., \& Enquist, B. (2009). Multiplicative by nature: Why logarithmic transformation is necessary in allometry. Journal of Theoretical Biology, 257(3), 519-521.
Kerkhoff, A. J., \& Enquist, B. J. (2006). Ecosystem allometry: The scaling of nutrient stocks and primary productivity across plant communities. Ecology Letters, 9, 419-427.

Khush, G. S. (1999). Green revolution: Preparing for the 21st century. Genome, 42(4), 646-655.

Körner, C. (2015). Paradigm shift in plant growth control. Current Opinion in Plant Biology, 25, 107-114.

Krausmann, F., Erb, K.-H., Gingrich, S., Haberl, H., Bondeau, A., Gaube, V., ... Searchinger, T. D. (2013). Global human appropriation of net primary production doubled in the 20th century. Proceedings of the National Academy of Sciences of the United States of America, 110(25), 10324-10329.

Kummu, M., De Moel, H., Porkka, M., Siebert, S., Varis, O., \& Ward, P. J. (2012). Lost food, wasted resources: Global food supply chain losses and their impacts on freshwater, cropland, and fertiliser use. Science of the Total Environment, 438, 477-489.

Lobell, D. B., Schlenker, W., \& Costa-Roberts, J. (2011). Climate trends and global crop production since 1980. Science, 333(6042), 616-620.

Lutz, W., \& Samir, K. C. (2011). Global human capital: Integrating education and population. Science, 333(6042), 587-592.

Malhi, Y., Doughty, C. E., Goldsmith, G. R., Metcalfe, D. B., Girardin, C. A. J., Marthews, T. R., ... Phillips, O. L. (2015). The linkages between photosynthesis, productivity, growth and biomass in lowland Amazonian forests. Global Change Biology, 21(6), 2283-2295.

Mann, C. C. (2018). The wizard and the prophet. New York, NY: Knopf.

Marques, A., Martins, I. S., Kastner, T., Plutzar, C., Theurl, M. C., Eisenmenger, N., ... Pereira, H. M. (2019). Increasing impacts of land use on biodiversity and carbon sequestration driven by population and economic growth. Nature Ecology and Evolution, 3(4), 628-637.

Mascaro, J., Litton, C. M., Hughes, R. F., Uowolo, A., \& Schnitzer, S. A. (2013). Is logarithmic transformation necessary in allometry? Ten, one-hundred, one-thousand-times yes. Biological Journal of the Linnean Society, 111(1), 230-233.

May, R. M. (1977). Thresholds and breakpoints in ecosystems with a multiplicity of stable states. Nature, 269(5628), 471-477.

Meadows, D. H., Meadows, D. L., Randers, J., \& Behrens, W. M., III. (1972). The limits of growth: A report for the Club of Rome's project on the predicament of mankind. New York, NY: Signet.

Mueller, N. D., Gerber, J. S., Johnston, M., Ray, D. K., Ramankutty, N., \& Foley, J. A. (2012). Closing yield gaps through nutrient and water management. Nature, 490(7419), 254-257.

Muggeo, V. M. R. (2008). Segmented: An R package to fit regression models with broken-line relationships. $R$ News, 8(1), 20-25.

Mellody, M., \& National Research Council. (2014). Can Earth's and society's systems meet the needs of 10 billion people?: Summary of a workshop. Washington, DC: National Academies Press.

Noy-Meir, I. (1975). Stability of grazing systems: An application of predator-prey graphs. Journal of Ecology, 63(2), 459-481.

Olson, D. M., Dinerstein, E., Wikramanayake, E. D., Burgess, N. D., Powell, G. V. N., Underwood, E. C., ... Kassem, K. R. (2001). Terrestrial ecoregions of the world: A new map of life on Earth provides an innovative tool for conserving biodiversity. BioScience, 51(11), 933-938.

Opdam, P., Luque, S., Nassauer, J., Verburg, P. H., \& Wu, J. (2018). How can landscape ecology contribute to sustainability science? Landscape Ecology, 33(1), 1-7.

Pandit, R., Scholes, R., Montanarella, L., Brainich, A., Barger, N., ten Brink, B., ... Willemen, L. (2018). Summary for policymakers of the assessment report on land degradation and restoration of the Intergovernmental Science-Policy Platform on Biodiversity and Ecosystem Services. Bonn, Germany: The Intergovernmental Platform on Biodiversity and Ecosystem Services.

Podobnik, B., Horvatic, D., Petersen, A. M., \& Stanley, H. E. (2009). Quantitative relations between risk, return and firm size. Europhysics Letters, 85(5), 50003. 
R Core Team. (2018). R: A language and environment for statistical computing. Vienna, Austria: R Foundation for Statistical Computing. Retrieved from http://www.R-project.org

Ray, D. K., Mueller, N. D., West, P. C., \& Foley, J. A. (2013). Yield trends are insufficient to double global crop production by 2050. PLoS ONE, 8(6), e66428.

Ritz, C., Baty, F., Streibig, J. C., \& Gerhard, D. (2015). Dose-response analysis using R. PLoS ONE, 10(12), e0146021.

Rodriguez-Iturbe, I., \& Rinaldo, A. (2001). Fractal river basins: Chance and self-organization. Cambridge, UK: Cambridge University Press.

Running, S. W. (2012). A measurable planetary boundary for the biosphere. Science, 337(6101), 1458-1459.

Sabin, P. (2013). The bet: Paul Ehrlich, Julian Simon, and our gamble over Earth's future. New Haven, CT: Yale University Press.

Scheffer, M. (2009). Critical transitions in nature and society. Princeton studies in complexity (Vol. 16). Princeton, NJ: Princeton University Press.

Sikkema, R., Dallemand, J. F., Matos, C. T., van der Velde, M., \& San-Miguel-Ayanz, J. (2017). How can the ambitious goals for the EU's future bioeconomy be supported by sustainable and efficient wood sourcing practices? Scandinavian Journal of Forest Research, 32(7), 551-558.

Šímová, I., \& Storch, D. (2017). The enigma of terrestrial primary productivity: Measurements, models, scales and the diversity-productivity relationship. Ecography, 40(2), 239-252.

Sitch, S., Smith, B., Prentice, I. C., Arneth, A., Bondeau, A., Cramer, W., ... Venevsky, S. (2003). Evaluation of ecosystem dynamics, plant geography and terrestrial carbon cycling in the LPJ dynamic global vegetation model. Global Change Biology, 9(2), 161-185.

Sponsel, L. E., Headland, T. N., \& Bailey, R. C. (Eds.) (1996). Tropical deforestation: The human dimension. New York, NY: Columbia University Press.

Stephenson, N. L., Das, A. J., Condit, R., Russo, S. E., Baker, P. J., Beckman, N. G., ... Alvarez, E. (2014). Rate of tree carbon accumulation increases continuously with tree size. Nature, 507(7490), 90-93.

Thurner, M., Beer, C., Ciais, P., Friend, A. D., Ito, A., Kleidon, A., ... Carvalhais, N. (2017). Evaluation of climate-related carbon turnover processes in global vegetation models for boreal and temperate forests. Global Change Biology, 23(8), 3076-3091.

Tilman, D., Balzer, C., Hill, J., \& Befort, B.L. (2011). Global food demand and the sustainable intensification of agriculture. Proceedings of the National Academy of Sciences of the United States of America, 108 20260-20264.

United Nations, Department of Economic and Social Affairs, Population Division. (2017). World population prospects: The 2017 revision, key findings and advance tables. ESA/P/WP/248. New York, NY: United Nations.

United Nations World Water Assessment Programme. (2018). The United Nations world water development report 2018: Nature-based solutions. Paris, France: UNESCO.

Van Deelen, T., \& Etter, D. (2003). Effort and the functional response of deer hunters. Human Dimensions of Wildlife, 8(2), 97-108.

Van Deynze, A., Zamora, P., Delaux, P.-M., Heitmann, C., Jayaraman, D., Rajasekar, S., ... Bennett, A. B. (2018). Nitrogen fixation in a landrace of maize is supported by a mucilage-associated diazotrophic microbiota. PLoS Biology, 16(8), e2006352.

Vitousek, P. M., Ehrlich, P. R., Ehrlich, A. H., \& Matson, P. A. (1986) Human appropriation of the products of photosynthesis. BioScience, 36(6), 368-373.

Vitousek, P. M., Mooney, H. A., Lubchenco, J., \& Melillo, J. M. (1997). Human domination of Earth's ecosystems. Science, 277(5325), 494-499.

West, G. B., Brown, J. H., \& Enquist, B. J. (1999). A general model for the structure and allometry of plant vascular systems. Nature, 400(6745), 664-667.

West, G. B., Enquist, B. J., \& Brown, J. H. (2009). A general quantitative theory of forest structure and dynamics. Proceedings of the National Academy of Sciences of the United States of America, 106(17), 7040-7045.

Whittaker, R. H., \& Likens, G. E. (1973). Primary production: The biosphere and man. Human Ecology, 1(4), 357-369.

Wilson, E. O. (2017). Half-Earth; our planet's fight for life. New York, NY: WW Norton.

Worm, B., \& Paine, R. T. (2016). Humans as a hyperkeystone species. Trends in Ecology and Evolution, 31(8), 600-607.

Wright, D. H. (1990). Human impacts on energy flow through natural ecosystems, and implications for species endangerment. Ambio, 19(4), 189-194.

Zhang, J., \& Yu, T. (2010). Allometric scaling of countries. Physica A: Statistical Mechanics and its Applications, 389(21), 4887-4896.

\section{BIOSKETCH}

Helmut Haberl and Karl-Heinz Erb work in sustainability science. Andrew Nevai is a mathematical biologist.

Dave Jenkins is an ecologist who enjoys unexplored territory between disciplines, because there be dragons. https://scholar. google.com/citations?user=0Fnd1DAAAAAJ\&hl.

\section{SUPPORTING INFORMATION}

Additional Supporting Information may be found online in the Supporting Information section.

How to cite this article: Jenkins DG, Haberl H, Erb K-H, Nevai AL. Global human "predation" on plant growth and biomass. Global Ecol Biogeogr. 2020;29:1052-1064. https://doi.org/10.1111/geb.13087 